\title{
The COVID-19 Pandemic: Challenges and Opportunities in Food Environments to Provide Sustainable Healthy Foods
}

\author{
Amiya Kumar Sahoo \\ \{sahooamiyakumar20@gmail.com\} \\ Department of Humanities and Social Sciences, Indian Institute of Technology (ISM) Dhanbad-826004, \\ Jharkhand, India
}

\begin{abstract}
The COVID-19 is a contagious disease caused by the novel coronavirus, widely spread throughout the globe. The outbreak of COVID-19 pandemic is a global health crisis that makes human health vulnerability, affects people's livelihood, disrupts and deteriorates the food environment and healthy nutritious food that are essential to sustain. This paper focuses on the food environment for sustainable healthy foods amidst COVID-19 outbreak. It provides insights into the challenges that arise in the food environment for healthy diets during the worldwide lockdown. It also highlights the opportunities for food environment at this juncture. This article highlights a healthy diet as a link between the food environment and nutrition. Worldwide, the diversity among countries due to their cultural, social, political, financial and agricultural potential will be an alternative pathway to the sustainability in the food environment in order to manage the epidemiological pandemic crisis in future.
\end{abstract}

Keywords: COVID-19; Food environment; Healthy diet; Sustainability

\section{Introduction}

The severe acute respiratory syndrome coronavirus 2 (SARS-CoV-2) causes novel coronavirus disease 2019 [1] -so-called COVID-19. It was recognized in the seafood market in Wuhan, Hubei, China in December 2019, and declared as a pandemic in March 2020 by World Health Organization [2]. This disease widely spreads in 188 countries and territories have reported over 27.4 million cases with more than 896000 deaths till the first week of September 2020 [3], where these numbers are growing daily. The vector of the coronavirus is a droplet from coughing and sneezing. The symptom of COVID-19 is like flue which includes cough, fever, breathing difficulties, sore throat, body aches [4]. The nature of the diseases is symptomatic (the incubation period varies from 2-14 days) as well as asymptomatic. Yet, there is no treatment or vaccine developed to combat the COVID-19 pandemic. The scientific world is searching for novel information and knowledge for management and preventive measure of this contagious virus outbreak. This disease is not deadly as compared to 
other pandemics such as Ebola virus disease, SARS and MERS [5]. However, the rapid transmission across the globe has become a major concern for government authorities and of scientific world. Several measures such as lockdown, travel ban, limit in transportation and advanced surveillance have been implemented to check the virus transmission [6] [7]. This disease is the greatest crisis in 21 st century which unrivalled humanitarian challenges and declining the world economy. The multi-facet COVID-19 pandemic has explored the susceptibility of the food environment. Throughout the world, there is a significant shortage of food due to disruption of the availability of labour during lockdown amidst COVID-19 pandemic [8]. This is the right time to think about sustainable and agri-food system at national and international levels within the food environment for the provision of a healthy diet.

The author investigates on challenges and opportunities in the food environment (farmers, traders, consumers) amidst COVID-19 outbreak as shown in fig.1. Subsequently, this article emphasizes on significant issues that food environment should address on healthy food during the pandemic juncture. The food security arose as a substantial issue- as agri-food trade indicates disruption within the supply chain due to lockdown. Next to this, food safety issue emerged in order to stay away from the transmission of coronavirus within the food supply chain (producers, retailers \& consumers). The requirement of nutritious diets for strong immunity and protection from infection among the consumers become a serious issue, as the production of needed products is slow down. The sustainability of food environment is another significant issue that should be addressed during the pandemic crisis in order to overcome in an emergency in future. The multidimensional food management and alternative food are the major concerns/ opportunities in the outbreak of a pandemic. 


\subsection{Challenges In Food Environment During Lockdown}

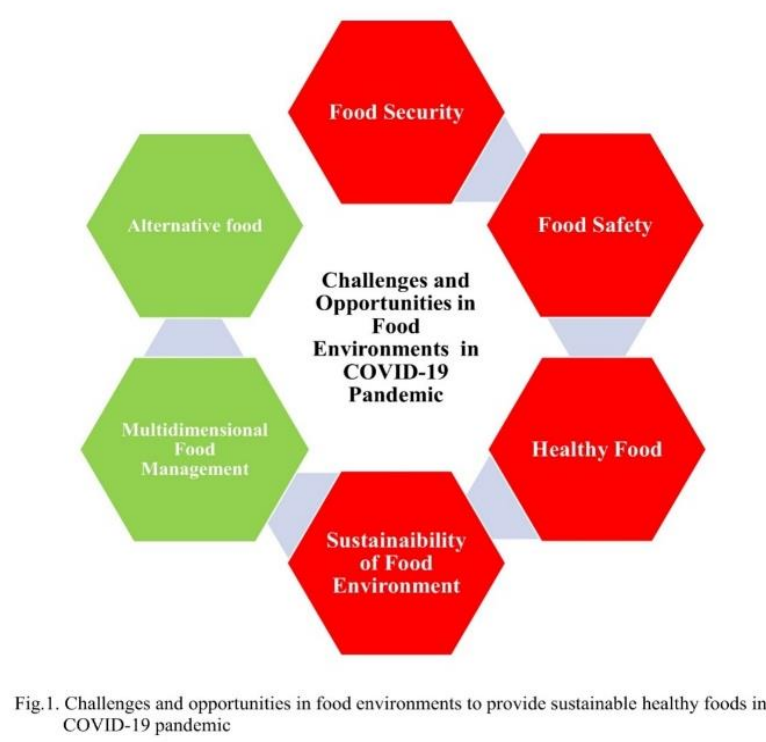

\section{a. Food Security}

Worldwide lockdown due to COVID-19 outbreak creates havoc that significantly constrains the food security by jeopardizing insufficient labour, transportation, agricultural production, retailers, consumers. The basic concept of food security is the availability and accessibility of healthy food along with cultural priority. According to the World Food Summit 1996 "food security exists when all people, at all-time, have physical and economic access to sufficient, safe and nutritious food that meets their dietary needs and food preferences for an active and healthy life" [9]. However, this pandemic scenario has an adverse impact on food security concerning lesser incomes, limited availability of food and so on [10]. As per the United Nations [11], the four aspects of food security such as availability, accessibility, utilization and stability has been affected due to outbreak of coronavirus disease [12]. The shortage of required food items, increase price and consumer attitude toward storing \& panic purchasing of foods are the major factors that impact food accessibility in lockdown. In the resource-poor settings, intake of nutritious and healthy foods is disastrous as food prices increase substantially with the proximity of informal market place. As discussed above, the outbreak of COVID-19 is dying out the food supply as well.

The importance of food security has already been incorporated into the global policy agenda in global food crisis 2008 [13]. A wide range of conceptual framework focuses on various dimensions and components such as 
accessibility, utilization, sustainability and quality, quantity, cultural preferences respectively at different levels like the individual, community, national and international have been implemented for monitoring and evaluation [14]; [15]; [16]; [17]; [18]; [19]. However, this pandemic crisis, food supply have been immensely interrupted and people are going bed with hunger. In this context, Food and Agricultural Organization (FAO) is proposing certain approaches for expanding emergency and immediate food assistance programme to the agricultural production via e-commerce for running of the supply chain [20]. Specific rules and regulations were implemented by China and Italy in the affected area such as Wuhan and Northern Italy region in the first month of COVID-19 pandemic to avoid acute food shortage. These measures are restricting on overcharging, illegitimate trade, and gathering of huge food products [21]. Likewise, other countries are keeping their food supply accessible to their population.

\section{b. Food Safety}

The scientific world is looking for solid information and strong evidence on the transmission mode of COVID-19. Though the mode of transmission of SARS and MERS seemed to be zoonotic [22]. As per the statement of the European Centre for Disease Prevention and Control (ECDC), the novel coronavirus is mainly transmitting through respiratory droplets of an infected individual to another individual [23]. The previous pandemic outbreaks such as SARS-coronavirus (SARS-CoV) and MERS-coronavirus (MERS-CoV) revealed that food is not a passage for transmission [24]; [25], and there is no concluding remark on SARS-CoV 2 (COVID-19) for the same. The transmission of this virus via food passages are possible if an infected person's foodstuff comes in contact with a healthy person, and will touch its mouth, nose or eyes [26]; [27]. Similarly, fresh foods may susceptible to get infection prior to frozen and may transmit the disease, as SARS-CoV-1 and MERS remains contagious in frosty condition [26].

Therefore, food packages vulnerable to coronavirus should be handled carefully with extensive sanitization to minimize the risk to get trapped in infection [28]. The Food and Drug Administration (FDA) recommended some precautionary measures like cleaning and sanitizing of surface for food, restaurants and kitchens. Besides these other measures like stopped serving foods, have been implemented by health authorities and restaurants. The preventive measures are taken to minimize the risk of cross-infection within foods as recommended by the World Health Organization (WHO), that are related to preparation practice and handling of food [29]; [30]. 


\section{c. Healthy Food}

Healthy food provides essential nutrients to the body and maintains good health. These foods include fruit and vegetable, functional foods and herbs that can rejuvenate immune function and maintain a healthy immune system. The healthy immune system helps to minimize the risk of getting trapped to infectious viruses [31]; [32]. The foods rich in vitamin ' $A$ ' and ' $C$ ' play a key role in enhancing various immune cell function and lower the vulnerable to infection [33]; [34]. Vitamin A is known as anti-inflammation vitamin and involved in the development of the immune system, that is effective in the treatment of various infectious disease such as TB, AIDS, Measles, acute Pneumonia, enteric infection, malaria [34]. Similarly, vitamin C is an antioxidant that defends against endogenous and exogenous oxidation and plays a significant role in enhancing the immune system. This is necessary as it fights against pathogens and controls viral infections such as acute respiratory tract infection and pneumonia [35]. Along with these nutritional supplements, vitamin $\mathrm{D}$ and $\mathrm{E}$ may boost our resistance to COVID-19 [36].

The traditional medicine is a key player in the treatment of various contagious viral diseases such as chickenpox, measles, influenza, genital herpes, hepatitis A, B, C and D [37], AIDS, respiratory diseases and hepatitis [38] and pneumonia [39] within the natural remedy. The medicinal plants are used in the treatment of these contagious diseases, at the same time various plant extracts such as fruits, tubers, shoots are also used as a food stuff that enhances the immune system. This traditional medicinal knowledge could have an alternative way for COVID-19. The effect of herbal medicine is significant in treatment of COVID-19 [40]. The healthy diets such as fruits, nuts, tubers, modified shoots with supplementary nutrition like vitamins, minerals may be a vehicle to rejuvenate a healthy immune system to overcome this pandemic.

\section{d. Sustainability of Food Environment}

The sustainable food environment encompasses a wide range of systems such as healthy food and agricultural system, economic and social system and their interlinked with each other. This food system provides healthy and nutritious food to all with sustainable practices all over the systems. "The Agenda 2030" of UN resolution declared 17 global goals for sustainable development goals (SDGs) to achieve a sustainable future for all. Food environment plays a vital role in achieving SDG2 that talks about "zero hunger, achieve food security and improved nutrition, and promote sustainable agriculture" [41] and SDG12 that talks about "responsible consumption and production pattern" [42]. The sustainable food environment should be 
investigated holistically with various dimensions such as social, environmental and economic in order to be sustainable.

However, the current food environment is not sustainable. The FAO study found that worldwide approximately one-third of food produced for human consumption is lost [43] and nearly $14 \%$ of food is lost in various stages such as agriculture, harvesting and processing before reaching retailer (State of Food and Agriculture 2019. Moving Forward on Food Loss and Waste Reduction|Policy Support and Governance| Food and Agriculture Organization of the United Nations, n.d.) [44]. According to United Nations report 2019, the population of the world could reach 9.7 billion in 2050 (Growing at a Slower Pace, World Population Is Expected to Reach 9.7 Billion in 2050 and Could Peak at Nearly 11 Billion around 2100, 2019) [45] that may lead food insecurity. Considering these phenomena, people living with high population density hunt for animal-based food sources. These animal-based food sources are key issues in food safety and hygiene, as bats are the host of SARS-CoV virus.

\subsection{Opportunities In Food Environment}

The outbreak of COVID-19 pandemic implies the exigency of reconsidering food environment. Besides the limited food security in the food environment, there is an opportunity to obtain food.

\section{a. Multidimensional Food Management}

To handle the critical situations in the food environment like loss and waste of food, we should promote and practice technology. It is necessary for the equidistributional of food and improves the communication between retailer and consumers by collecting the real-time data using various technology such as apps, information and communication technology, big data and artificial technology. Use of ICT in the food environment could enhance the agri-food sustainability that increases and improves productivity, food chain coordination and minimize inefficiency as well as management cost [46]. Green technology could be implemented for production and process in the food system. Food must be processed with various technique to transform raw produce into value-added food that ensures safety and quality life [47] . ICT can revolutionize the food environment as it has the capacity of adaptability, affordability and accessibility. It encourages the stakeholders in the supply food chain for easy, quick, efficiently and accuracy performance. It helps in bridging the communication gap and improved prediction and monitoring that is useful in fight against hunger and buil up a sustainable system. 


\section{b. Alternative Food}

This is the right time on the food environment for triggering measure that food supply chain is going on to lower the risk on vulnerable groups. The present system of food is not sustainable as it is solely dependent on animal-protein based and other related dimensions such as health and food security and environmental. The rapid growth of population leads to the growing demand for proteins and exhaustion of resources. This leads the scientific world to explore more possibilities of sustainable food sources in order to endure the desired need [48]. In the meantime, scholars have developed cockroach milk [49] that is a protein-rich crystalized substance and cockroach flour [50] as a next superfood. Besides these, microalgae could be the alternative protein sources in the fourth coming food environment [48].

\section{Conclusion}

The pandemic burden of COVID-19 outbreak has taught a lesson to the world. We are still searching for the consequences of humanity in terms of social, economic and environmental. This pandemic crisis may strengthen the capability of the food environment to work in an integrated way with other systems (e.g., health, environment) in a holistic manner. The food environment becomes more susceptible in interruption to production, distribution and acquisition. This pandemic threatens the prosperity and wellbeing of the most vulnerable group of people. There are significant challenges in the contemporary scenario toward food safety, food security and quality of food as discussed above. 


\section{Reference}

[1] Sanders, J. M., Monogue, M. L., Jodlowski, T. Z., \& Cutrell, J. B. (2020). Pharmacologic treatments for coronavirus disease 2019 (COVID-19): A review. Jama, 323(18), 1824-1836.

[2] Ghebreyesus, T. A. (2020). WHO Director-General's opening remarks at the media briefing on COVID-19-11 March 2020. World Health Organization, 11.

[3] University, J. H. (2020). COVID-19 dashboard by the center for systems science and engineering (CSSE).

[4] Fisher, D., \& Heymann, D. (2020). Q\&A: The novel coronavirus outbreak causing COVID-19. BMC Medicine, 18(1), 1-3.

[5] Klaus, I. (2020). Pandemics are also an urban planning problem. CityLab (6 March 2020).

[6] Djalante, R., Shaw, R., \& DeWit, A. (2020). Building resilience against biological hazards and pandemics: COVID-19 and its implications for the Sendai Framework. Progress in Disaster Science, 100080.

[7] Shaw, R., Kim, Y., \& Hua, J. (2020). Governance, technology and citizen behavior in pandemic: Lessons from COVID-19 in East Asia. Progress in Disaster Science, 100090.

[8] Huff, A. G., Beyeler, W. E., Kelley, N. S., \& McNitt, J. A. (2015). How resilient is the United States' food system to pandemics? Journal of Environmental Studies and Sciences, 5(3), 337 347.

[9] FAO. (1996). World food summit: Rome declaration on world food security and World Food summit plan of action. FAO.

[10] Devereux, S., Béné, C., \& Hoddinott, J. (2020). Conceptualising COVID-19's impacts on household food security. Food Security, 12(4), 769-772.

[11] FAO, A. (2008). An introduction to the basic concepts of food security. FAO, Rome, Italy.

[12] Niles, M. T., Bertmann, F., Belarmino, E. H., Wentworth, T., Biehl, E., \& Neff, R. A. (2020). The Early Food Insecurity Impacts of COVID-19. MedRxiv.

[13] Mangnus, E., \& Van Westen, A. C. M. (2018). Roaming through the maze of maize in northern Ghana. A systems approach to explore the long-term effects of a food security intervention. Sustainability, 10(10), 3605

[14] Asih, D. N., \& Klasen, S. (2017). Improving food security? Setting indicators and observing change of rural household in Central Sulawesi. Forest and Society, 1, 154-161.

[15] Coates, J., Swindale, A., \& Bilinsky, P. (2007). Household Food Insecurity Access Scale (HFIAS) for measurement of food access: Indicator guide: version 3.

[16] Harris-Fry, H., Azad, K., Kuddus, A., Shaha, S., Nahar, B., Hossen, M., Younes, L., Costello, A., \& Fottrell, E. (2015). Socio-economic determinants of household food security and women's dietary diversity in rural Bangladesh: A cross-sectional study. Journal of Health, Population and Nutrition, 33(1), 2.

[17] Ike, C. U., Jacobs, P. T., \& Kelly, C. (2017). A multidimensional approach to measuring household food security in Taraba State, Nigeria: Comparing key indicators. Development in Practice, 27(2), 234-246.

[18] Leroy, J. L., Ruel, M., Frongillo, E. A., Harris, J., \& Ballard, T. J. (2015). Measuring the food access dimension of food security: A critical review and mapping of indicators. Food and Nutrition Bulletin, 36(2), 167-195.

[19] SATI, V. P. (2017). Enhancing Food Security through Sustainable Agriculture in Uttarakhand Himalaya. Productivity, 58(2).

[20] Cullen, M. (2020). COVID-19 and the risk to food supply chains: How to respond. FAO. Recuperado de Http://Www. Fao. Org/3/Ca8388en/CA8388EN. Pdf.

[21] Galanakis, C. M. (2020). The Food Systems in the Era of the Coronavirus (COVID-19) Pandemic Crisis. Foods, 9(4), 523.

[22] Das, U. N. (2020). Can Bioactive Lipids Inactivate Coronavirus (COVID-19)? Archives of Medical Research. 
[23] $Q \&$ A on COVID-19: Basic facts. (n.d.). European Centre for Disease Prevention and Control. Retrieved September 10, 2020, from https://www.ecdc.europa.eu/en/covid-19/facts/questionsanswers-basic-facts

[24] Coronavirus: No evidence that food is a source or transmission route. (2020, March 9). European Food Safety Authority. https://www.efsa.europa.eu/en/news/coronavirus-noevidence-food-source-or-transmission-route

[25] Nutrition, C. for F. S. and A. (2020). Food Safety and the Coronavirus Disease 2019 (COVID19). FDA. https://www.fda.gov/food/food-safety-during-emergencies/food-safety-andcoronavirus-disease-2019-covid-19

[26] CDC. (2020, June 16). Coronavirus Disease 2019 (COVID-19)-Transmission. Centers for Disease Control and Prevention. https://www.cdc.gov/coronavirus/2019-ncov/prevent-gettingsick/how-covid-spreads.html

[27] für Risikobewertung, B. (2020). Can the new type of coronavirus be transmitted via food and objects.

[28] Natalie Seymour, M. Y. (2020, May 20). COVID-19 and Food Safety FAQ: Is Coronavirus a Concern with Takeout? Food Science and Human Nutrition. https://edis.ifas.ufl.edu/fs349

[29] COVID-19 and Food Safety: Guidance for Food Businesses. (n.d.). Retrieved September 10, 2020, from https://www.who.int/publications-detail-redirect/covid-19-and-food-safetyguidance-for-food-businesses

[30] Nutrition and Food Safety and COVID-19. (n.d.). Retrieved September 10, 2020, from https://www.who.int/teams/nutrition-and-food-safety/covid-19

[31] Gibson, A., Edgar, J. D., Neville, C. E., Gilchrist, S. E., McKinley, M. C., Patterson, C. C., Young, I. S., \& Woodside, J. V. (2012). Effect of fruit and vegetable consumption on immune function in older people: A randomized controlled trial. The American Journal of Clinical Nutrition, 96(6), 1429-1436.

[32] Naik, S. R., Thakare, V. N., \& Joshi, F. P. (2010). Functional foods and herbs as potential immunoadjuvants and medicines in maintaining healthy immune system: A commentary. Journal of Complementary and Integrative Medicine, 7(1).

[33] Hemilä, H. (1997). Vitamin C intake and susceptibility to pneumonia. The Pediatric Infectious Disease Journal, 16(9), 836-837.

[34] Huang, Z., Liu, Y., Qi, G., Brand, D., \& Zheng, S. G. (2018). Role of vitamin A in the immune system. Journal of Clinical Medicine, 7(9), 258

[35] Carr, A. C., \& Maggini, S. (2017). Vitamin C and Immune Function. Nutrients, 9(11) https://doi.org/10.3390/nu9111211

[36] Wang, L., Wang, Y., Ye, D., \& Liu, Q. (2020). A review of the 2019 Novel Coronavirus (COVID-19) based on current evidence. International Journal of Antimicrobial Agents, 105948.

[37] A, N. N. R., L, K. M. M., A, T. T., H, M. N., R, M. C. P., Z, M. B., M, E. E. R., F, N., L, B., \& H, A. Z. P. (2011). Ethnobotanical survey of some Cameroonian plants used for treatment of viral diseases. African Journal of Plant Science, 5(1), 15-21. https://doi.org/10.5897/AJPS.9000106

[38] Kitazato, K., Wang, Y., \& Kobayashi, N. (n.d.). Viral infectious disease and natural products with antiviral activity. 9.

[39] Lin, L., Yan, H., Chen, J., Xie, H., Peng, L., Xie, T., Zhao, X., Wang, S., \& Shan, J. (2019). Application of metabolomics in viral pneumonia treatment with traditional Chinese medicine. Chinese Medicine, 14(1), 8. https://doi.org/10.1186/s13020-019-0229-x

[40] Ang, L., Song, E., Lee, H. W., \& Lee, M. S. (2020). Herbal Medicine for the Treatment of Coronavirus Disease 2019 (COVID-19): A Systematic Review and Meta-Analysis of Randomized Controlled Trials. Journal of Clinical Medicine, 9(5). https://doi.org/10.3390/jcm9051583

[41] Goal 2: Zero hunger. (n.d.). UNDP. Retrieved September 10, 2020, from https://www.undp.org/content/undp/en/home/sustainable-development-goals/goal-2-zerohunger.html 
[42] Goal 12: Responsible consumption and production. (n.d.). UNDP. Retrieved September 10, 2020, from https://www.undp.org/content/undp/en/home/sustainable-development-goals/goal12-responsible-consumption-and-production.html

[43] Global food losses and food waste. (n.d.). Retrieved September 10, 2020, from http://www.fao.org/3/mb060e/mb060e00.htm

[44] Growing at a slower pace, world population is expected to reach 9.7 billion in 2050 and could peak at nearly 11 billion around 2100. (2019, June 17). UN DESA | United Nations Department of Economic and Social Affairs. https://www.un.org/development/desa/en/news/population/world-population-prospects2019.html

[45] State of Food and Agriculture 2019. Moving forward on food loss and waste reduction|Policy Support and Governance| Food and Agriculture Organization of the United Nations. (n.d.). Retrieved September 10, 2020, from http://www.fao.org/policy-support/tools-andpublications/resources-details/en/c/1242090/

[46] El Bilali, H., \& Allahyari, M. S. (2018). Transition towards sustainability in agriculture and food systems: Role of information and communication technologies. Information Processing in Agriculture, 5(4), 456-464.

[47] Boye, J. I., \& Arcand, Y. (2013). Current trends in green technologies in food production and processing. Food Engineering Reviews, 5(1), 1-17.

[48] Galanakis, C. M. (2019). Proteins: Sustainable source, processing and applications. Academic Press.

[49] Niaz, K., Zaplatic, E., \& Spoor, J. (2018). Highlight report: Diploptera Functata (cockroach) milk as next superfood. EXCLI Journal, 17, 721

[50] de Oliveira, L. M., da Silva Lucas, A. J., Cadaval, C. L., \& Mellado, M. S. (2017). Bread enriched with flour from cinereous cockroach (Nauphoeta cinerea). Innovative Food Science \& Emerging Technologies, 44, 30-35. 